\title{
Diversity regarding Confucian values in the Korean Workplace: Assessing the moderating roles of formalization, courtesy inkunja leadership, and team efficacy
}

\author{
SuyoungRyu \\ Chungnam National University \\ School of Business \\ 99,Daehak-ro, Yuseon-gu \\ Daejeon, 305-764, South Korea.
}

\begin{abstract}
This study examined how diversity regarding Confucian values influences the performance of teams working in Korean corporations under Confucian culture. Additionally, it examined the roles of formalization, courtesy in kunja leadership (KL), and team efficacy in mitigating the negative effects of value-related diversity. To address these issues, data on 79 teams, including 349 individuals and 79 team leaders, were collected from representative public and private Korean corporations. The results show that neither diversity in Confucian values among members, nor between a team leader and team members, was significantly associated with team performance. This study also found that the moderating effects of formalization, courtesy in KL, and team efficacy were variable, and that differences in leaders' and members' Confucian values had consistently negative effects on team performance in situations subject to such moderation.
\end{abstract}

Keywords: Diversity in Confucian values, Formalization, Courtesy in kunjaleadership, Team efficacy, Team performance

\section{Introduction}

Globalization and the diffusion of Western value systems into management practices worldwide have increased value-related diversity at the workplace in Korea. For example, the greater involvement in international business of Cheabols, which is the term used to describe Korean conglomerate groups, has led to the adoption of a Western, especially American, management style characterized such as rationalization, individualism, external feedback, and short-term performance goals. Under the direction of the International Monetary Fund (IMF) in particular, this phenomenon has accelerated (see Jang et al., 2003) and diversity in Confucian values has increased within corporate organizations.

Confucian values, traditionally emphasizing obedience to authority and filial piety, have had important roles in modern Korean society since the Chosun dynasty employed them as a ruling principle. Confucian values guide the behavior of individuals, teams and organizations, and are prioritized over all other alternatives. However, the influence of Confucian values has been weakening with the adoption of a Western management style in corporate organizations, and this trend has increased diversity in Confucian values among employees. For example, practices and attitudes such as showing respect for elders, feeling loyalty to and commitment to the organization one belongs to, and receiving higher compensation and advance in office according to degree of seniority, have been eroded by the focus on individual interests and capacity(see Lee \& Lee, 2014). Thus, individuals have developed a deep interest in their own performance and career development instead of prioritizing good relationships with colleagues or displaying organizational commitment.

Cultural values have an important role in shaping an individual's social identity (Brewer \&Yuki, 2007; Roccas\& Brewer, 2002), which incorporates the concept of the self, feelings, thoughts, and behaviors, and the integration of groups members into a single, cooperative team entity. An individual in a group or team is not independent of their environment and adheres to the shared identity of that group. The self-categorization theory (SCT) of Turner et al. (1987) is an extension of social identity theory and refers to the tendency to distinguish between 'we' and 'others' according to social standing. It can be applied to the situation wherein there are different cultural values within a team. In such a case, members with different degrees of Confucian values may identify with each other outside of the group context, reducing their intention to cooperate to improve team performance. However, how the diversity in Confucian values among members of work teams in Korea influences team performance has not yet been investigated.

This study focuses on how diversity regarding Confucian values influences team performance in Korean corporations operating under Confucian culture. Additionally, to elucidate the factors that serve to strengthen this relationship, the roles of formalization, courtesy in kunja leadership (KL), and team efficacy, which may mitigate the negative effects of value-related diversity, were examined. Using a hypothesis-driven approach, I hope that this study will provide a fresh perspective through which to analyze diversity in the workplace of collective cultures. 


\section{Theoretical background and hypotheses}

\subsection{Diversityregarding Confucian values and performance}

Values form a foundation for human behavior and identity (Brewer \& Yuki, 2007; Dose, 1999; Roccas\& Brewer, 2002), guiding individuals' decisions about how they should or ought to behave (Meglino\&Ravlin, 1998) and signifying what is important in life (Bardi\& Schwartz, 2003). Watson et al. (1993) showed that a culturally diverse work group initially performed much more poorly in terms of group processes, range of perspectives, problem identification, generation of alternatives, quality of solutions, and overall performance than did a homogenous work group. To the extent that multiple subcultures exist in moderately heterogeneous teams, conflict is potentially maximized (Earley\&Mosakowski, 2000; Lau \&Murnighan, 1998) and inter-team interaction and communication may be blocked (Alexander et al., 1995; Blau, 1977). Klein et al. (2011) also suggested that differences in values may lead team members to disagree about priorities and reasonable goals, about who should do what and when, and about appropriate styles of work and communication.

Confucianism has served as a governing principle in terms of social relationships in East Asia for more than 2,000 years. In Confucian societies, keeping social order and creating harmony in human relationships takes priority over individual interests. Thus, avoiding conflict and competition is considered as a virtue. However, globalization and the diffusion of Western values, characterized primarily by individualism, including the prominence of individual interests, enhanced competition, and a merit-based pay system within teams, have resulted in the co-existence of diverse values.Applying SCT to this issue of diversity in cultural values indicates thatteam members categorize themselves according to the strength of their Confucian values. Thus, this diversity in values may threaten traditional means of communicating and decision-making, and the beliefs of members regarding desirable characteristics, such as maintaining harmony and respect for the elderly, and may lead to serious conflicts in decision-making processes, such as when horizontal and vertical communications clash, leading to fundamental problems and difficulties in solving them. These dynamics can have negative effects on team performance. In particular, differences between a team leader who holds Confucian values and team members who do not may lead to serious vertical conflicts as well as nonacceptance of task assignments and goals, resulting in the selection of an inappropriate solution and ultimately poor team performance. Thus, diversity regarding Confucian values may be associated with negative team outcomes. The study hypotheses were as follows:

Hypothesis 1a: The degree towhich team members differ regarding Confucian values will benegatively associated with team performance.

Hypothesis 1b: The degree to which a leader's Confucian values differ from those of team members will be negatively associated with team performance.

\subsection{The moderating effects of formalization}

Formalization refers to documented jobs and includes their procedures, rules, roles, and operational procedures (Aliken\&Hage, 1966; Hage, 1965).Zucker (1986) suggested that institutions are a source of trust, while Kerr and Jermier (1997) argued that formalization lessens the importance of a leader. In other words, formalization facilitates trust and substitutes for the positive effects of leadership based on trust.Establishing roles and responsibilities in diverse teams will mitigate role conflictsand reduce negative effects of value-related diversity on team performance. For example, Seong and Hong (2013) observed that cooperative group norms, reflecting shared objectives, mutual interests, and commonalities among members, all reduced the negative effect of the relationship between gender diversity and team commitment.

Mischel and Northcraft (1997) noted that a work team's success depends not only on its ability to perform a task but also on its ability to effectively manage its own interactions, including communicating and engaging in cooperative and coordinated collective efforts. If a team shares behavioral norms (e.g., a team has concrete procedures, and the job descriptions of members clearly delineate responsibility, authority, and accountability), the members may havea sense of social identity within that team. In other words, members may perceive themselves as'us',not 'others'. Thus, the level of team harmony will be high and intra-team conflicts will be effectively controlled. In other words, formalization will contribute to affording the sense of social identity as well as reducing transactional costs such as exchanging opinions or monitoring the appropriate choice of action, and enhance team trust through the clarity of roles and responsibilities. The study hypotheses were as follows:

Hypothesis 2a:Formalization will reduce the negative effects of diversity regarding Confucian values among team membersonteam performance.

Hypothesis 2b: Formalization will reduce the negative effects of diversity regarding Confucian values between a team leader and team members on team performance. 


\subsection{The moderating effects of courtesy inkunja leadership}

Leadership is a critical contributor to team performance, especially when thecharacteristics of team members arevaried (Chemers\& Murphy, 1995). It fosters a positive team climate in which different opinions are freely expressed and collaboration includes debate, open communication, trust, and respect. For example, the leadership style of a leader in a diverse team may determine the extent to which ideas and experiences are freely shared among team members (Oldham \& Cummings, 1996), which contributes to the quality of the team's performance.

Social identity is important for predicting who will likely be accepted and perceived as a leader (Hogg, 2001). Culture influences acceptance of leadership behaviors, and is fundamental to developing the identity ofa leader (Van Knippenberg, Van Knippenberg, De Cremer, \&Hogg, 2004). Thus, leadership is a socially constructed concept and cannot be adequately understood without taking into account the social and cultural contexts in which it operates (Biggart\& Hamilton, 1987; Ryu, 2015).

Kunjaleadershipis defined as the process by which a leader influences team members to agree, with the objective of achieving upper-level goals, and to voluntarily cooperate to improve performance, by practicing moral virtues and creating the sense of community (Ryu, 2009). The practice of KL is derived from the notion of a kunja, i.e.,an ideal moral leader in East Asia under Confucianism, who becomes a leader only after cultivating his or her own virtues. Virtues in this context refer to the five constant values that comprise a human being according to Confucianism: humanity, righteousness, courtesy, wisdom, and trustworthiness.

According to the definition of KL, the goal of this leadership style is to create the sense of community by practicing moral virtues in managerial roles (Ryu,2009, 2015).Especially, courtesy in KL refers to 'modesty', i.e., not being arrogant about one's abilities but rather humbling oneselfin front of other people. It also refers to 'temperance', thatis, expressing one's emotions without making others uncomfortable andcontrolling one's greed, and 'respect for order', whichrefers to following rules and order, as decreed bysociety. Additionally, courtesy in KL refers to constantly and sincerely practicing gmodesty, temperance, and respect for order to decrease tensions and conflicts among diverseindividuals, to ultimately achieveharmony (Ryu\& Lee, 2010). Confucius particularly emphasized courtesy in human relationships and argued that a ruler should treat his subjectsin a courteous manner; otherwise, people become unruly and strife becomes rampant.

Ryu and Lee (2010) found that the five constant values of KL were all positively associated with trust in a leader; in particular, courtesy had the strongest association. A leader who incorporates socially justified Confucian virtues and leads in a courteous manner will be closer to the prototypically ideal leader and thus instill trust and cooperation among team members. Moreover, the smaller the degree of diversity in Confucian values among team members, the larger the effect of courtesy in KL on team performance. The study hypotheses were as follows:

Hypothesis 3a:Courtesy in KL willhave a markedly more positive effect on team performance when the difference in Confucian values among team members is small.

Hypothesis 3b: Courtesy in KL will have a markedly more positive effect on team performance when the difference in Confucian values between a team leader and team members is small.

\subsection{The moderating effects of team efficacy}

Team efficacy refers to team members' shared perceptions about the degree to which their team is capable of performing a specific task, which is similar to an individual believing in their own abilities (Bandura, 1997). The sense of team efficacy often arises from already established reputations, experiences, and fair social exchanges among members of a team. If team members have had positive experiences in the past with other team members, they will have high expectations of those team members' abilities, role efficacy, and their assumption of appropriate responsibility in the future. Bandura (1982, 1986, and 1997) suggested that team efficacy influences what people choose to do as a team and how much effort they put into it. Several studies found that collective efficacy was related to team performance (Campion et al., 1996; Gibson, 1999; Gully et al., 2002; Guzzo et al., 1993; Lee \&Farh, 2004; Myers, Feltz, \& Short, 2004; Prussia \&Kinicki, 1996).

When a team is diversely composed on purpose, it is expected that different occupational backgrounds and experiences will contribute to the sharing of different information and knowledge and will result in balanced decisions. However, if a team has a low level of shared cultural values, among members and with the team leader, individuals in the team perceive differences more rather than similarities and have a low tendency toward cooperation to achieve goals. Thus, the positive effect of team efficacy will be decreased or absent. The study hypotheses were as follows:

Hypothesis 4a: Team efficacy will have a markedly more positive effect on team performance when the difference in Confucian values among team members is small.

Hypothesis 4b: Team efficacy will have a markedly more positive effecton team performance when the difference in Confucian values between the team leader and team members is small. 


\subsection{Research models}

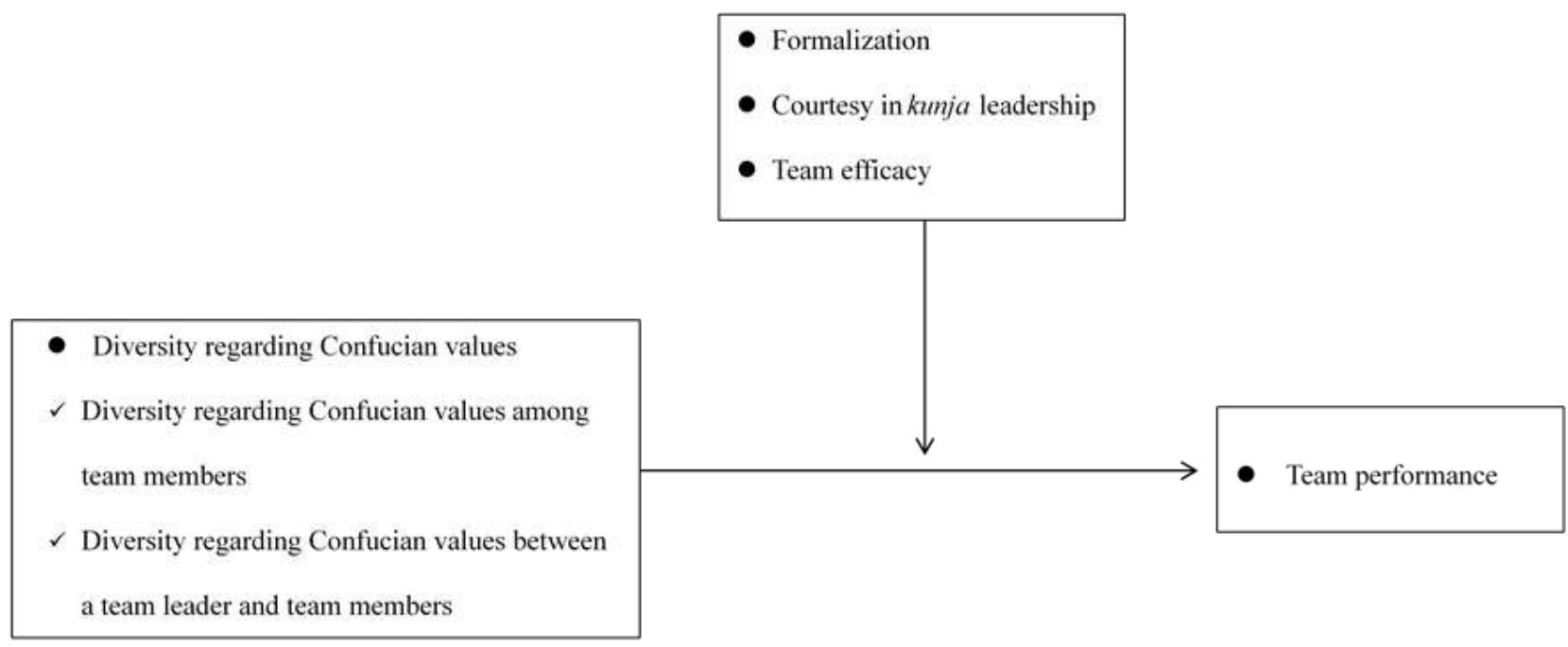

\section{Methods}

\subsection{Procedures}

To examine the relationship between diversity and team performance, and to investigate the moderating effects of formalization, courtesy in KL, and team efficacy, I contacted human resources directors to ask for their assistance in the distribution and collection of questionnaires at the team level. 'Teams' in this study refers to work units in a department, while 'team leaders' refers to formal, responsible team managers.

\subsection{Participants}

The questionnaires were distributed among representative Korean public and private corporations. Data regarding 79 teams, including 349 individuals and 79 team leaders, were analyzed after excluding incomplete or seemingly frivolous responses, as well as teams whose team leader did not respond. The sample of 349 individuals was $79 \%$ male; $16.52 \%$ of respondents were in their 20 s, $58.55 \%$ in their $30 \mathrm{~s}, 21.16 \%$ in their $40 \mathrm{~s}$, and $3.77 \%$ in their $50 \mathrm{~s}$; $8.75 \%$ had a high school diploma, 9.33\% had a college degree, and $81.92 \%$ had a master's degree or higher; $28.78 \%$ were employees, $29.97 \%$ were deputies, $30.27 \%$ were section chiefs, $7.72 \%$ were deputy heads of department, and $3.26 \%$ were heads of department. The average term working with the team leader was 30.78 months. The sample of 79 team leaders was $98 \%$ male; $6.25 \%$ of respondents were in their $30 \mathrm{~s}, 86.25 \%$ in their $40 \mathrm{~s}, 6.25 \%$ in their $50 \mathrm{~s}$, and $1.25 \%$ in their $60 \mathrm{~s} ; 3.75 \%$ had a high school diploma, $1.25 \%$ had a college degree, and $63.85 \%$ had a master's degree or higher. The average term taking charge of a team was 34.37 months. Industry information was obtained from the team leaders: $26.58 \%$ of the industries were stock firms, $11.39 \%$ were communication companies, $13.92 \%$ were construction companies, $10.13 \%$ were in the service industry, $31.65 \%$ were in the energy industry, and $6.33 \%$ were manufacturing companies.

\subsection{Variables}

\subsubsection{Diversity regarding Confucian values}

Differences regarding Confucian values among team members were measured in terms of standard deviations, and the difference of a team leader's Confucian values in relation to those of team members was measured through differences in the absolute value. Eight Korean Confucian values, adapted from Ryu's (2007) study, were measured; the values reflect self-cultivation, maturity, and maintenance of the social order using a scale ranging from 1 (never important) to 7 (very important) to rate the degree to which the items corresponded to the respondents' behavior and mentality in their everyday lives. Some example items included conscience, attitude of endeavor, discretion in speaking and acting, respect and obedience to the old, justification, generosity of mind, filial piety, and integrity.

\subsubsection{Team performance}

Team performance was evaluated based on data from team members. Team members rated five items drawn from the research conducted by Hallam and Campbell (1997) on a 7-point scale: quality of work, achieving allocated goals, satisfaction with work product, positive evaluation, and outstanding success. The averages of these scores were used. The justification indices for the aggregate data from team members, in the form of the average interrater reliability (rwg (j)), the intra-class correlation coefficient (ICC (1)), and the inter-class correlation coefficient (ICC (2)), which relates to inter-rater agreement, were $0.94,0.32$, and 0.68 , respectively. 


\subsubsection{Team formalization}

Team formalization was defined and measured in terms of whether a team had clearly documented policies, goals and objectives for performing tasks, and clear procedures or job descriptions that clarified responsibility, authority, and accountability (Podsakoff\& Mackenzie, 1994). Three items were adapted from Podsakoff and Mackenzie (1994), and team members used a scale ranging from 1 (very different) to 7 (very similar) to rate their team with respect to the various team formalization parameters. The average scores were used in the analysis. The average values of rwg (j), ICC (1), and ICC (2) were $0.82,0.20$, and 0.53 , respectively.

\subsubsection{Courtesy in kunjaleadership}

Courtesy in KL is defined as a leadership style that incorporates moral virtues such as modesty, temperance, and respect for order, and ultimately orients toward harmony. Eight items were adapted from Ryu's (2009) work: modesty, moderation, ability to control one's tendency toward self-interest, overcoming any difficulties within a team or department by collaborating with other members in challenging times, being polite to team members, being modest even after achieving success, clarifying the scope of member's tasks and their roles, and abiding by the norms and principles of the organization. Team members used a scale from 1 (very different) to 7 (very similar) to rate the degree to their current manager's leadership style was reflected in these items. The average rwg (j), ICC (1), and ICC (2) values were $0.93,0.21$, and 0.55 , respectively.

\subsubsection{Team efficacy}

Team efficacy refers to team members' shared perceptions about the degree to which their team is capable of performing a specific task (Bandura 1997). This variable was measured using the five items developed by Jung and Sosik (2002). Team members used a scale ranging from 1 (strongly disagree) to 7 (strongly agree) to rate the degree to which each item reflected their colleagues' work attitudes and behavior. The average of these scores was used. The averages of the rwg (j), ICC (1), and ICC (2) were $0.95,0.27$, and 0.63 , respectively.

\subsubsection{Control variables}

Industry type, team size, and team leader's tenure were controlled after reviewing previous research (Bogart \&Lundgen, 1974; Gist et al., 1987; Kahai et al., 2003; Stahl et al., 2009; Steiner, 1972; Wheelan, 2009).

\section{Results}

Table 1 presents the basic statistics and correlations between variables; the $\alpha$ coefficient appears on the diagonal in parentheses. According to these data, formalization, courtesy in KL, and team efficacy were significantly positively correlated with team performance $(\mathrm{r}=0.24, \mathrm{p}<0.05$ to $\mathrm{r}=0.81, \mathrm{p}<0.001)$.

Table 1 Descriptive statistics and correlations $\left(N_{\text {team }}=79, N_{\text {members }}=349\right)$

\begin{tabular}{|c|c|c|c|c|c|c|c|c|}
\hline Variables & Mean & $S D$ & 1 & 2 & 3 & 4 & 5 & 6 \\
\hline 1. Formalization & 5.43 & 0.64 & $(0.76)$ & 0.57 & -0.01 & -0.12 & 0.64 & 0.25 \\
\hline 2. Courtesy in kunja leadership & 4.59 & 0.68 & & $(0.98)$ & -0.07 & -0.16 & 0.49 & 0.24 \\
\hline 3. Team efficacy & 5.46 & 0.57 & & & $(0.91)$ & 0.05 & -0.23 & 0.81 \\
\hline $\begin{array}{l}\text { 4. Diversity regarding Confucian } \\
\text { values among team members (TM) }\end{array}$ & 0.47 & 0.23 & & & & & 0.27 & -0.03 \\
\hline $\begin{array}{l}\text { 5.Diversity regarding Confucian values } \\
\text { between a team leader and TM }\end{array}$ & 0.62 & 0.42 & & & & & & -0.19 \\
\hline 6.TM evaluation & 5.25 & 0.68 & & & & & & $(0.90)$ \\
\hline
\end{tabular}

Note. $\alpha$ coefficientreliabilities are shown in parentheses.

$|\mathrm{p}|>0.19, p<0.05$

$|\mathrm{p}|>0.32, p<0.001$

Table 2 presents the results of the analyses of relationships between diversity regarding Confucian values and team performance. Controlled-for variables including industry type, team size, and team leader's tenure were not statistically significant and are thus not presented in Table 2 . All other variables were normalized against the grand mean of each variable to solve multi-collinearity problems. Step 1 in Table 2 shows the main effects of diversity regarding Confucian values. 
The degree to which team members differ regarding Confucian values, and the degree to which a leader's Confucian values differ from those of team members, did not have statistically significant main effects on team performance. Thus, hypotheses $1 \mathrm{a}$ and $1 \mathrm{~b}$ were not statistically supported.

Table 2Effects of team diversity and team performance as moderated by formalization, courtesy in kunjaleadership, and team efficacy $\left(\mathbf{N}_{\text {team }}=79\right)$

\begin{tabular}{|c|c|c|c|}
\hline Step 1: Main effects & Team performance & $F$ value & $\operatorname{Adj}-R^{2}$ \\
\hline $\begin{array}{l}\text { Diversity regarding Confucian values (DCV) among team } \\
\text { members }\end{array}$ & -0.03 & $3.54 * *$ & 0.23 \\
\hline DCV between a team leader and members & -0.05 & & \\
\hline
\end{tabular}

Step 2: Effects of formalization

\begin{tabular}{|c|c|c|c|}
\hline Formalization $(\mathrm{F})$ & $0.60 * * *$ & $10.46^{* * *}$ & 0.60 \\
\hline DCV among team members $\times F$ & $0.21 *$ & & \\
\hline DCV between a team leader and members $\times F$ & $-0.28 * *$ & & \\
\hline
\end{tabular}

Step 3: Effects of courtesy in kunja leadership

\begin{tabular}{|c|c|c|c|}
\hline Courtesy in kunjaleadership (CKL) & $0.40 * * *$ & $5.14 * * *$ & 0.39 \\
\hline $\mathrm{DCV}$ among team members $\times \mathrm{CKL}$ & 0.12 & & \\
\hline DCV between a team leader and members $\times$ CKL & $-0.17 \dagger$ & & \\
\hline
\end{tabular}

\section{Step 4: Effectsofteam efficacy}

\begin{tabular}{|c|c|c|c|}
\hline Team efficacy (TE) & $0.71 * * *$ & $15.47 * * *$ & 0.69 \\
\hline DCV among team members $\times \mathrm{TE}$ & 0.01 & & \\
\hline DCV between a team leader and members $\times \mathrm{TE}$ & $-0.20 *$ & & \\
\hline
\end{tabular}

Note. Standardized $\beta$-values are presented.

$\dagger p<0.10$

$* p<0.05$

$* * p<0.01$

$* * * p<0.001$

Step 2 in Table 2 presents the main effects and the interaction effects of formalization. Formalization was significantly positively associated with team performance $(\beta=0.60, p<0.001)$. Furthermore, formalization significantly positively moderated the relationship between diversity regarding Confucian values among team members and team performance $(\beta=0.21, \mathrm{p}<0.05$; see Figure 2 (a)) as hypothesis 2 (a) proposed. However, contrary to expectations, formalization significantly negatively moderated the relationship between the difference between leaders' and team members' Confucian values and team performance $(\beta=-0.28, \mathrm{p}<0.01$, see Figure 2 (b)). 
Fig. 2 Effects of the interaction between diversity regarding Confucian values and formalization on team performance

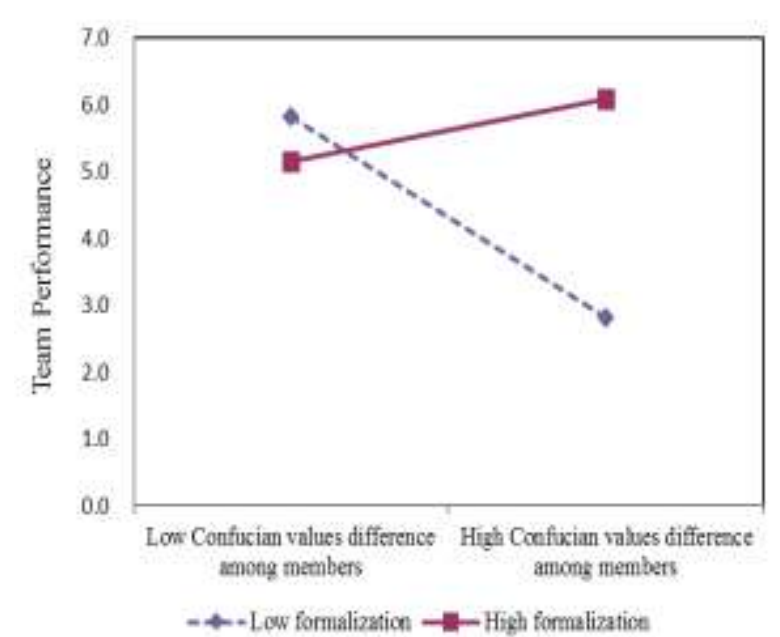

(a)The effect oftheinteraction betweendiversity regarding Confucian values among members and formalization on performance.

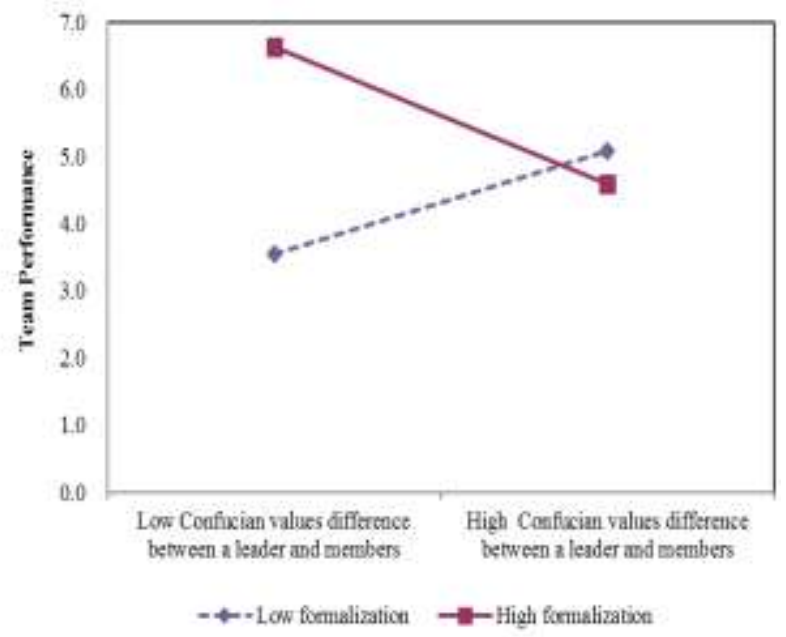

(b)The effect of the interaction between diversity regarding Confucian values between a team leader and team membersandformalizationon performance.

Step 3 in Table 2 shows the direct and moderating effects of courtesy in KL on the relationship between diversity regarding Confucian values and team performance. The results show that courtesy in KL was positively associated with team performance $(\beta=0.40, \mathrm{p}<0.001)$ and that it showed a trend toward negatively moderating only the relationship between the difference between leaders' and team members' Confucian values and team performance $(\beta=-0.17, p<0.10$; see Figure 3), as proposed by hypothesis $3 b$.

Fig. 3 Effect of the interaction of differences regarding Confucian values between a team leader and team members and courtesy in kunja leadership on performance.

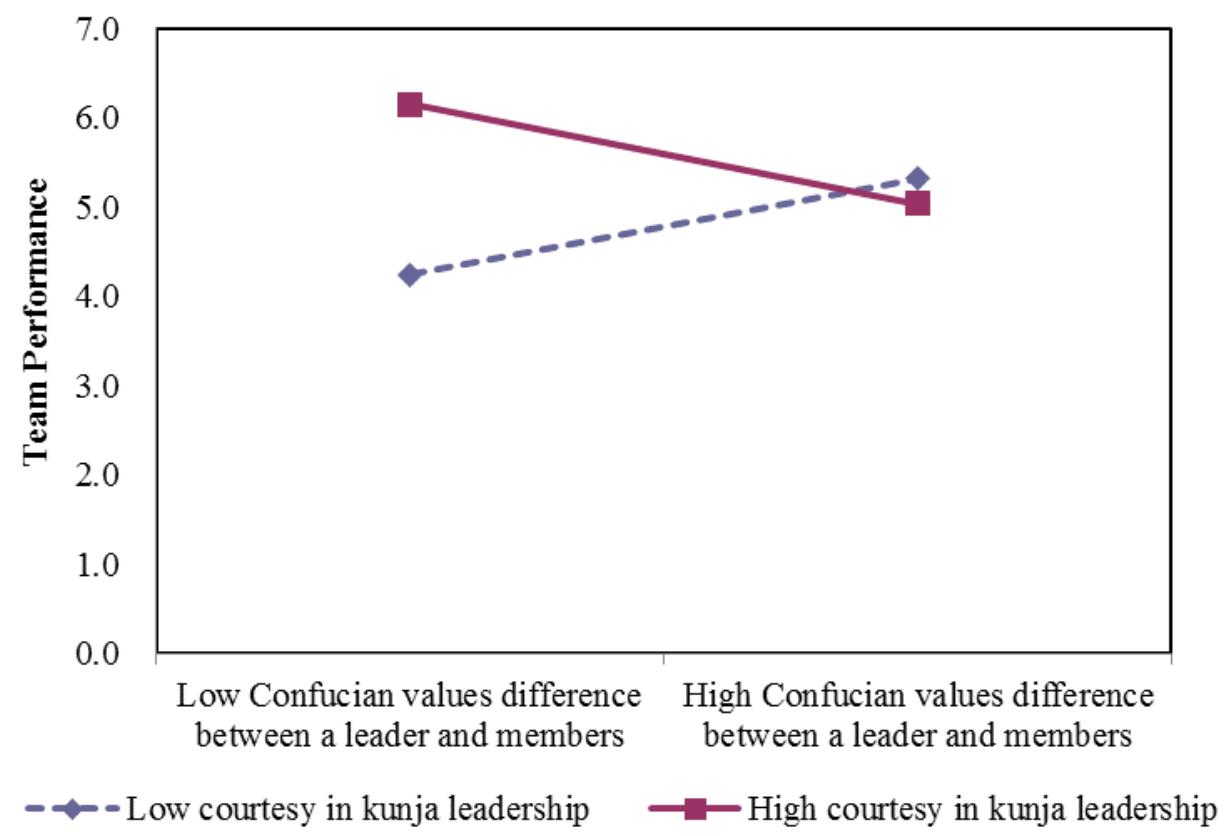

Step 4 in Table 2 shows the main and interaction effects of team efficacy on the relationship between diversity regarding Confucian values and team performance. Team efficacy had significantly positive main effects on team performance $(\beta=0.71, p<0.001)$. Additionally, the results indicate that team efficacy negatively moderated only the relationship between the difference of the leader's Confucian values with those of team members and team performance $(\beta=-0.20, p<0.01$; see Figure 4$)$ as hypothesis $4 \mathrm{~b}$ proposed. 


\section{Fig. 4 Interaction effects of differences with regard to Confucian values between a team leader and team members and team efficacy in relation to performance}

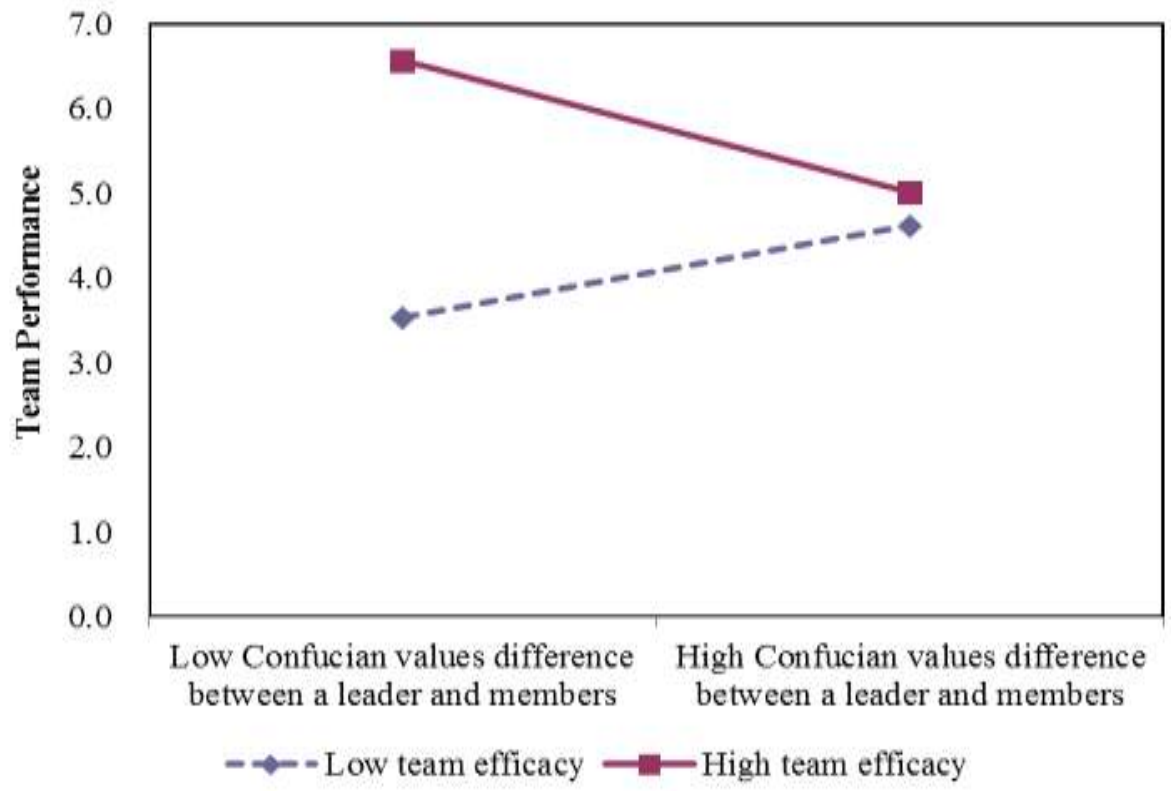

\section{Discussion}

This paper examined two research questions. First, is diversity regarding Confucian values, among team members and between a team leader and team members, associated with team performance? Second, do formalization, courtesy in KL, and team efficacy moderate the relationships between diversity regarding Confucian values and team performance, and if so, what are the mechanisms? The results show that neither diversity in Confucian values among team members, nor between a team leader and team members, was significantly associated with team performance. These results suggest that the process of socialization for adapting the organizational culture may reinforce the homogeneity of the Korean workforce and offset the positive or negative effects of diversity regarding Confucian values in work teams. Moreover, as Schneider's (1987) attraction-selection-attrition theory suggests, the Korean workforce has a strong collectivist culture and those not fitting with this culture are already ruled out by human resource policies, so that differences in Confucian values may be minimal and thus not exert major effects.

Next, analyses of moderating effects of formalization on team performance were complex. The mixed results of formalization imply a dual role. That is, when formalization is considered a shared behavioral norm, it produces institutional trust and neutralizes the negative effects of diversity in Confucian values on performance. However, when formalization is combined with a hierarchical structure such as the difference between a leader's Confucian values and those of team members, it strengthens the negative effects of diversity regarding Confucian values.

The effect of courtesy in KL was positively associated with team performance, and was strengthened when the degree of diversity regarding Confucian values between a team leader and team members was small, as hypothesized. These results support the importance of social identity in leadership, to which Hogg (2001) referred, which stresses the importance of social identity for understanding who will be perceived as a leader and which types of managerial behaviors will be accepted. However, the results were only weakly statistically supported (at the 0.10 significance level) and courtesy in KL did not significantly moderate the relationship between diversity regarding Confucian values among team members and team performance. Thus, these mixed results suggest follow-up studies for re-examination of the effect of ruling courteously, as emphasized by Confucius.

Finally, team efficacy was positively associated with team performance, with the association being stronger when the difference between leaders' and members' Confucian values was small. This result partially supports the SCT of Tuner et al. (1987). When a team is characterized by a low level of shared cultural values between members and the team leader, they perceive many more differences than similarities to each other and have a low tendency toward cooperating to achieve goals, as reflected in lower team efficacy. However, this effect was not seen in the case of diversity regarding Confucian values among members.

This study has some important implications. First, the dual effects of formalization and courtesy in KL within a Confucian culture suggests that it would be useful to expand data collection efforts to countries such as China and Vietnam, which are still largely under Confucianism. Additionally, this study attempted to dichotomize diversity regarding Confucian values, i.e., by assessing such diversity among team members, and between a team leader and 
members.

One important finding was that differences in leaders' and members' Confucian values had consistently negative effects on team performance in proposed moderating context. It is clear, then, that companies should strive to minimize such differences. Finally, enhancing team efficacy is important for improving performance, and efforts to reduce the gap between leaders' and members' Confucian values are required to fully exploit the benefits of team efficacy.

\section{Conclusions}

First, this study identified two effects of formalization on diversity-related variables and performance. When formalization is perceived as a proxy for hierarchy, it strengthens the negative relationship between the difference between leaders' and members' Confucian values and team performance. On the other hand, when it is perceived as a norm or principle guiding members' behavior, it mitigates the negative effects of diversity, as it serves to generate trust in the institution as Zucker (1986) indicated. These two roles of formalization reflect the cultural effects of a large power distance, as described by Hofstede (2001). Summarizing, given that Confucianism is embedded in hierarchical human relationships, formalization may negatively influence vertical relationships and positively affect horizontal relationships.

Second, this study identified diversity among team members regarding Confucian values and the difference between leaders' and members' Confucian values. The results are interesting in that the difference between leaders' and members' Confucian values was negatively interrelated with formalization and team efficacy on team performance. Additionally, this study found that formalization, courtesy in KL, and team efficacy were directly positively associated with team performance, and these positive effects were diminished when the difference between leaders' and members' Confucian values was high.

\section{References}

Alexander, J., Nuchols, B., Bloom, J., \& Lee, S. 1995. Organizational demography and turnover: An examination of multiform and nonlinear heterogeneity. Human Relations, 48(12): 1455-1480.

Bandura, A. 1982. Self-efficacy mechanism in human agency. American Psychologist, 37(2): 122-147.

Bandura, A. 1986. Social foundations of thought and action. Prentice-Hall, Englewood Cliffs, NJ.

Bandura, A. 1997. Collective efficacy. In A. Bandura (Ed.), Self-efficacy: The exercise of control (pp. 477-525). NY: Freeman.

Bardi, A., \& Schwartz, S. H. 2003. Values and behavior: Strength and structure of relations. Personality and Social Psychology Bulletin, 29(10): 1207-1220.

Bell, S. T., Villado, A. J., Lukasik, M. A., Belau, L., \& Briggs, A. 2011. Getting specific about demographic diversity variable and team performance relationships: A meta-analysis, Journal of Management, 37(3): 709-743.

Biggart N. W., \& Hamilton, G. G. 1987. An institutional theory of leadership. Journal of Applied Behavioral Science, 23(4): 429-441.

Blau, P. M. 1977. Inequality and heterogeneity. NY: Free Press.

Bogart, D., \& Lundgren, D. 1974. Group size, member dissatisfaction, and group radicalism. Human Relations, 27(4): 339-355.

Brewer, M. B., \& Yuki, M. 2007. Culture and social identity. In S Kitayama and D Cohen (eds.) Handbook of cultural psychology, 307-322, NY: The Guilford Press.

Campion, M. A., Papper, E. M., \&Medsker, G. J. 1996. Relations between work team characteristics and effectiveness: A replication and extension. Personnel Psychology, 49(2): 429-452.

Chemers, M. M., \& Murphy, S. E. 1995. Leadership and diversity in groups and organizations. In M. M. Chemers, S. Oskamp, \& M. A. Costanzo (Eds.), Diversity in organizations: New perspectives for a changing workplace (pp. 157-190). Thousand Oaks, CA: SAGE Publications, Inc.

Combs, G. M. 2002. Meeting the leadership challenge of a diverse and pluralistic workplace: Implications of selfefficacy for diversity training. Journal of Leadership Studies, 8(4): 1-16.

Dose, J. J. 1999. The relationship between work values similarity and team member and leader-member exchange relationships. Group Dynamics: Theory, Research, and Practice, 3(1): 20-32.

Earley, P. C., \&Mosakowski, E. 2000. Creating hybrid team cultures: An empirical test of transnational team functioning. Academy of Management Journal, 43(1): 26-49.

Gibson, C. B. 1999. Do they do what they believe they can? Group efficacy and group effectiveness across tasks and cultures. Academy of Management Journal, 42, 138-152.

Gist, M., Locke, E., \& Taylor, M. 1987. Organizational behavior: Group structure, process, and effectiveness. Journal of Management, 13(2): 237-257. 
Guzzo, R. A., Yost, P. R., Campbell, R. J., \&Shea, G. P. 1993. Potency in groups: Articulating a construct. British Journal of Social Psychology, 32: 87-106.

Gully, S. M., Incalcaterra, K. A., Joshi, A., \&Beaubien, J. M. 2002. A meta-analysis of team-efficacy, potency, and performance: Interdependence and level of analysis as moderators of observed relationships. Journal of Applied Psychology, 87(5): 87819-832.

Hage, J. 1965. An axiomatic theory of organization. Administrative Science Quarterly, 10(3): 289-320.

Hallam, G., \& Campbell, D. 1997. The measurement of team performance with a standardized survey. In M. T. Brannick, E. Salas, \& C. Prince (Eds.), Team performance assessment and measurement: Theory, methods, and applications (pp. 155-171). Mahwah, New Jersey: Lawrence Erlbaum Associates, Inc.

Hofstede, G. (2001) Culture's consequences: Comparing values, behaviors, institutions, and organizations across nations (2nd ed.), Thousand Oaks, CA: SAGE.

Hogg, M. A. 2001. A social identity theory of leadership. Personality and Social Psychology Review, 5(3): 184200.

Horwitz, S. K., \&Horwitz, I. B. 2007. The effects of team diversity on team outcomes: A meta-analytic review of team demography. Journal of Management, 33(6): 987-1015.

Jung, D. I., \&Sosik, J. J. 2002. Transformational leadership in work groups: The role of empowerment, cohesiveness, and collective-efficacy on perceived group performance. Small Group Research, 33(3): 313336.

Kahai, S. S., Sosik, J. J., \&Avolio, B. J. 2003. Effects of leadership style, anonymity, and rewards on creativityrelevant processes and outcomes in an electronic meeting system context. The Leadership Quarterly, 14(45): 499-524.

Kerr, S., \&Jermier, J. M. 1978. Substitutes of leadership: Their meaning and measurement. Organizational Behavior and Human Performance, 22(3): 375-403.

Klein, K. J., Knight, A. P., Ziegert, J. C., Lim, B. C., \&Saltz, J. L. 2011. When team member's values differ: The moderating role of team leadership. Organizational Behavior and Human Decision Processes, 114(1): 2436.

Lau, D. C., \&Murnighan, J. K. 1998. Demographic diversity and fault line: The compositional dynamics of organizational groups. Academy of Management Review, 23(2): 325-340.

Lee, C., \&Farh, J. 2004. Joint effects of group efficacy and gender diversity on group cohesion and performance. Applied Psychology: An International Review, 53(1), 136-154.

Meglino, B. M., \&Ravin, E. C. 1998. Individual values in organizations: Concepts, controversies, and research. Journal of Management, 24(3): 351-389.

Mischel, L. J., \&Northcraft, G. B. 1997. I think we can, I think we can...: The role of self-efficacy beliefs in group and team effectiveness. In B. Markovsk\& M. J. Lovaglia (Eds.), Advances in group processes, 14 (pp. 177-197). Greenwich, CT: JAI Press.

Myers, N. D., Feltz, D. L., \& Short, S. E. 2004. Collective Efficacy and Team Performance: A Longitudinal Study of Collegiate Football Teams. Group Dynamics: Theory, Research, and Practice, 8(2): 126-138. DOI: 10.1037/1089-2699.8.2.126

Oldham, G. R., \& Cummings, A. 1996. Employee creativity: Personal and contextual factors at work. Academy of Management Journal, 39(3): 607-634.

Prussia, G. E., \&Kinicki, A. J. 1996. A motivational investigation of group effectiveness using social-cognitive theory. Journal of Applied Psychology, 81(2): 187-198.

Roccas, S., \& Brewer, M. B. 2002. Social identity complex. Personality and Social Psychology Review, 6(2): 88106.

Ryu, S. Y. 2007. Item development for Korean Confucian values. Korean Journal of Management, 19(2): 171-205.

Ryu, S. Y. 2009. A study on Kunja's leadership concept, measurement and effectiveness (Unpublished doctoral dissertation). Seoul National University, Seoul.

Ryu, S. Y., \& Lee, K. 2010. The impacts of kunja's leadership on group efficacy and group cohesion: The mediating effect of trust in the leader. Korean Academy of Organization and Management, 34(4): 29-59.

Ryu, S. Y. 2012. The impact of group diversity and Kunja leadership on group performance. Korean Journal of Industrial and Organizational Psychology, 25(1): 27-58.

Ryu, S. Y. 2015. Kunja leadership: Concept and nomological validity. Leadership \& Organizational Development Journal, 37(6): 744-764. http://dx.doi.org/10.1108/LODJ-12-2013-0167

Schneider, B. 1987. The people make the place. Personnel Psychology, 40(3): 437-453.

Seong, J. Y., \& Hong, D. 2013. Gender diversity: How can we facilitate its positive effects on teams? Social Behavior Personality, 41(3): 497-508. 
Stahl, G. K., Maznevski, M. L., Voigt, A., \&Jonsen, K. 2009. Unraveling the effects of cultural diversity in teams: A meta-analysis of research on multicultural work groups. Journal of International Business Studies, 41(4): 690-709.

Turner, J. C., Hogg, M. A., Oakes, P. J., Reicher, S. D., \&Wetherell, M. S. 1987. Rediscovering the social group: A self-categorization theory. NY: Basil Blackwell.

Van Knippenberg, D., Van Knippenberg, B., De Cremer, D., \& Hogg, M. A. 2004. Leadership, self, and identity: A review and research agenda. The Leadership Quarterly, 15(6): 825--856.

Watson, W. E., Kumar, K., \&Michaelsen, L. K. 1993. Cultural diversity's impact on interaction process and performance: Comparing homogeneous and diverse task groups. Academy of Management Journal, 36(3): 590-602.

Wheelan, S. A. 2009. Group size, group development, and group productivity. Small Group Research, 40(2): 247262.

Zucker, L. G. 1986. Production of trust: Institutional sources of economic structure, 1840 1920, In B. M. Staw\& L. L. Cummings (Eds.). Research in Organizational Behavior, 8 (pp. 53-111), Greenwich, CT: JAI Press. 